\title{
Parando de beber: estágios de mudança vividos por ex-alcoolistas
}

\section{Drinking cessation: ex-alcoholic change stages and experiences}

\author{
Sheila Giardini MURTA' \\ Bartholomeu Torres TRÓCCOLI
}

\begin{abstract}
Resumo
Este estudo descreve como ex-alcoolistas vivenciaram estágios de mudança a fim de parar de beber, nas fases de contemplação, preparação, ação e manutenção. Cinco ex-alcoolistas foram entrevistados acerca de fatores facilitadores e dificultadores da mudança e estratégias de enfrentamento usadas em cada fase. Exposição a situações aversivas associadas ao beber foi relatada como o principal fator facilitador da mudança nos estágios anteriores à ação e o suporte social foi o principal fator facilitador nos estágios de ação e manutenção. Ganhos associados ao beber foram o principal fator dificultador da mudança em todas as fases. As principais estratégias de enfrentamento relatadas foram busca de suporte social e esquiva de situações de risco para o beber. São discutidas implicações para intervenção e novos estudos.
\end{abstract}

Palavras-chave: alcoolismo; comportamento de beber; enfrentamento; modelo transteórico.

\begin{abstract}
This study describes how ex-alcoholic adults have experienced change stages in drinking cessation, at stages of contemplation, preparation, action and maintenance. Five ex-alcoholics were interviewed about factors that hampered and helped the change, and coping strategies used for every stage. Exposition to aversive situations associated to drinking was reported as the strongest helpful factor in preparation stage, as the social support was in action and maintenance stages. Benefits associated to drinking were the most relevant factors that hampered change in all stages. The most important coping strategies related were asking for social support and avoidance from risk situations to drink. Implications to intervention and new researches are discussed.
\end{abstract}

Key words: alcoholism; drinking behavior; coping behavior; transtheoretical model.

Há evidências de que a modificação do comportamento de abuso de álcool pode ocorrer com e sem ajuda profissional. Diversos estudos têm documentado efeitos de programas de intervenção profissional sobre a redução do consumo de álcool (O'Farrel, Gutter, Choquette, Floyd \& Bayog, 1992; Marlatt, Larimer, Baer \& Quigley, 1993; Sobell, Sobell \&
Gavin, 1995; O'Farrel, Choquette, Gutter, Brown, Bayog, McCourt, Lowe, Chan \& Deneault 1996). Contudo, relativamente poucas teorias têm discutido sobre o processo de mudança que produz tais efeitos, ou como as pessoas mudam. Exceção é o Modelo de Mudança Transteórico (Prochaska, DiClemente \& Norcross, 1992), construído originalmente para descrever o processo

\section{$\boldsymbol{v} \nabla \boldsymbol{v}$}

1 Departamento de Psicologia, Universidade Católica de Goiás. Avenida Universitária, 1440, Setor Universitário, 74605-010, Goiânia, GO, Brasil. Correspondência para/Correspondence to: S.G. MURTA.E-mail:<murta@cultura.com.br>.

2 Instituto de Psicologia, Universidade de Brasília. Brasília, DF, Brasil. 
de mudança relativo ao abandono do comportamento de fumar. Na década de 80, um estudo conduzido por DiClemente e Prochaska (1982) com ex-fumantes que haviam mudado com e sem intervenção profissional identificou que os dois grupos haviam passado por estágios semelhantes de mudança, desde o não querer mudar (pré-contemplação), o desejo inicial de mudar (contemplação), tomar iniciativas para implementar a mudança (preparação), mudar (ação), até manter a mudança (manutenção). Recaídas em qualquer das etapas podem ocorrer, assim como a retomada da mudança voltando a estágios anteriores, de modo cíclico, à semelhança de uma espiral (Prochaska, Redding \& Evers, 1997).

Nas duas últimas décadas, instrumentos de avaliação têm sido desenvolvidos e validados (Yoshida, 2002) e evidências consistentes e crescentes acerca das características dos estágios de mudança propostos pelo Modelo de Mudança Transteórico têm sido descritas na literatura (Prochaska \& DiClemente, 1983; DiClemente, Prochaska, Fairhurst, Velicer, Velasquez \& Rossi, 1991; Pers, DiClemente \& Carbonari, 1996). Indivíduos em fase de pré-contemplação mostram-se resistentes em reconhecer que necessitam mudar, desconsiderando a possibilidade de mudar. Na fase seguinte, contemplação, o indivíduo encontra-se consciente de que necessita mudar, mas ainda não toma nenhuma iniciativa para que a mudança ocorra. A pessoa sabe o que quer, mas não está pronta para se comprometer efetivamente com a mudança; considera fatores favoráveis, desfavoráveis e conseqüências de mudar ou não mudar, experimentando ambivalência frente à mudança durante meses ou até anos. A fase de preparação é caracterizada por intenção de mudar acompanhada de tentativas malsucedidas de fazê-lo, sem engajamento em ações eficazes. Nessa fase ocorre a tomada de decisão quanto à implementação de ações que de fato levam à mudança. É nesse estágio que se estabelece a prontidão para mudar, que culminará no estágio da ação. Nesse estágio, são modificados comportamentos e ambiente para que a mudança de fato exista. $\mathrm{O}$ estágio de ação é assim considerado se a mudança já estiver ocorrendo entre um dia até seis meses. A partir de seis meses, ocorre a última fase, que é a manutenção da mudança, quando se trabalha para consolidar a mudança e evitar recaídas (Lichtenstein \& Glasgow, 1992; Jungerman \& Laranjeira, 2001).

Atualmente, o Modelo de Mudança Trans-teórico tem sido utilizado para fundamentar avaliação e intervenção em diversos campos, tais como psicologia da saúde (Orleans, 2000), saúde pública (Oldenburg, 1994) e psicoterapia (Yoshida, 2002). No tratamento de comportamentos aditivos, caracte-rísticas de cada estágio têm sido consideradas para o planejamento de intervenção e de estratégias para lidar com a resistência de pessoas que estão entre a pré-contemplação e a contemplação. Dentre os procedimentos desenvolvidos, incluem-se entrevistas empáticas que produzam motivação suficiente para tomada de decisão para mudar (Miller \& Rollnick, 2001), procedimentos de solução de problemas para lidar com a ambivalência típica do estágio de contemplação (Jungerman \& Laranjeira, 2001) e controle de estímulos de eventos desencadeadores do comportamento de beber, identificando situações de alto risco e desenvolvendo estratégias variadas para lidar com elas (Knnap \& Bertolote, 1994).

Nessa perspectiva, manter-se sem beber é entendido como o resultado do uso de diversas habilidades aprendidas. Tal processo de aprendizagem pode incluir lapsos, como voltar a beber em um fim de semana festivo. Para evitar que lapsos ocorram e se transformem em recaídas permanentes, um repertório baseado em auto-eficácia, autocontrole, assertividade e em diversas estratégias de enfrentamento deve ser gradativamente adquirido (Marllatt \& Gordon, 1993).

Por conseguinte, o enfrentamento ativo da pessoa que tem problemas com o beber se configura como um aspecto crucial na manutenção para a mudança. Há evidências de que o estilo de enfrentamento é uma variável mediadora do consumo de álcool (Maisto, Connors \& Zywiak, 2000). Habilidades para lidar com situações de alto risco para desencadear o beber, tais como situações de problemas interpessoais, frustração ou pressão social (Marllat \& Gordon, 1993), podem ser definitivas para que haja ou não abuso de álcool.

Enfrentamento se refere ao modo como o indivíduo lida com uma situação adversa ou estressora; seu uso no contexto de comportamentos aditivos designa o modo de lidar com situações de alto risco. 
De acordo com Lazarus e Folkman (1984), o enfrentamento pode ser definido como "os esforços cognitivos e comportamentais em constante mudança usados para manejar demandas específicas internas e/ou externas que são avaliadas como sobrecarregando ou excedendo os recursos da pessoa" (p.141). Essa definição de enfrentamento salienta que: (a) a demanda a ser enfrentada pode ser relativa ao ambiente externo (pública) ou interno (privada); (b) o que define a demanda são seus atributos subjetivos e não os objetivos, conforme avaliação feita pelo indivíduo a partir de sua história particular de interação com o meio; (c) a resposta de enfrentamento pode consistir em comportamento privado ("esforço cognitivo", como pensar sobre as estratégias disponíveis para solução do problema) ou público ("esforço comportamental", como pedir orientação a alguém), englobando um variado e amplo conjunto de respostas e (d) enfrentamento é um processo dinâmico ("esforços em constante mudança"), que consiste em respostas situacionais resultantes da interação entre indivíduo e ambiente, cada qual com características, necessidades, recursos e limitações particulares.

No modelo de enfrentamento de Lazarus e Folkman (1984), as diferentes respostas de enfrentamento podem ser agrupadas em dois estilos de enfrentamento: focado no problema e focado na emoção. O primeiro consiste no uso de estratégias que visam remover o evento ameaçador ou reduzir o seu impacto (exemplo: buscar informações sobre o problema), enquanto o segundo consiste no uso de estratégias que visam reduzir os sentimentos provocados pelo evento ameaçador (exemplo: relaxamento).

Tem sido proposto que o enfrentamento a situações de alto risco para o beber pode incluir habilidades focadas no problema, tais como habilidades para identificar situações de risco, planejar estratégias para prevenir sua ocorrência ou para sair da situação quando ela já estiver ocorrendo ou ainda para lidar com situações inescapáveis. Essas habilidades representam habilidades sociais, habilidades de autocontrole, de solução de problemas e auto-eficácia (Knnap \& Bertolote, 1994). Uma suposição é que o desenvolvimento desse conjunto de habilidades em pessoas que desejam parar de beber, com ou sem apoio profissional, é uma das vias que favorecem as fases de ação e manutenção.

Dado o caráter contextual do enfrentamento, é razoável supor que haja respostas diferenciadas de enfrentamento aos diversos estágios de mudança em relação ao abandono do álcool. É possível que as estratégias de enfrentamento requeridas sejam diferentes para o indivíduo que esteja considerando a possibilidade de parar de beber (contemplação), que esteja decidido a mudar (preparação), que tenha abandonado recentemente o álcool (ação) ou que esteja vivendo sem beber há vários meses (manutenção).

O entendimento dos fatores que facilitam o parar de beber é considerado relevante por produzir conhecimento com aplicabilidade direta em programas de promoção de saúde, tanto preventivos quanto remediativos. No entanto, estudos focados no entendimento desse processo têm sido escassos em nosso meio. Na tentativa de contribuir para o preenchimento dessa lacuna, este artigo descreve um estudo de caso em uma pequena amostra de ex-alcoolistas, e investiga como foram vividos os estágios de mudança em relação ao abandono do alcoolismo, desde o desejo inicial de parar de beber até a manutenção, e quais as estratégias de enfrentamento usadas em cada estágio. Os objetivos específicos do estudo foram descrever eventos (a) facilitadores e (b) dificultadores da mudança nos estágios de contemplação, preparação, ação e manutenção e (d) as estratégias de enfrentamento utilizadas para lidar com fatores dificultadores em cada estágio.

\section{Estudo de Caso}

Participaram voluntariamente cinco ex-alcoolistas, sendo três homens e duas mulheres, com idades entre 25 e 51 anos e instrução variando entre segundo e terceiro grau. Todos os participantes já haviam passado pelos estágios de pré-contemplação, contemplação, preparação e ação em relação ao parar de beber e estavam em fase de manutenção. O tempo de uso do álcool variou entre doze e trinta anos, e o tempo de abandono variou entre três anos e três meses e vinte 
anos. Os participantes foram recrutados através de um grupo de ajuda mútua para ex-alcoolistas.

\section{Instrumento}

Foi utilizado um roteiro de entrevista semi-estruturada contendo treze questões sobre eventos facilitadores e dificultadores do desejo de parar de beber, das iniciativas para parar de beber, do parar de beber e da manutenção da mudança e estratégias de enfrentamento usadas em cada estágio. Dentre as treze questões, quatro eram sobre a fase de contemplação (exemplo:"O que te fez pensar em parar de beber?"), três sobre a fase de preparação (exemplo: "Quando você estava decidindo parar de beber, havia alguma situação que dificultava a sua decisão?"), duas sobre a fase de ação (exemplo: "Que iniciativas você tomou para começar a abandonar a bebida?") e quatro sobre a fase de manutenção (exemplo:"Desde a sua última recaída, o que você tem feito para ter forças para ficar sem beber?").

\section{Procedimento}

Contatou-se um grupo de auto-ajuda para ex-alcoolistas, no qual foram recrutados os participantes em potencial. Todos concordaram em participar após serem informados sobre cuidados éticos através do termo de consentimento informado. A entrevista foi feita individualmente, gravada em áudio, em um tempo médio aproximado de 50 minutos. Os dados foram transcritos e submetidos à análise de conteúdo (Bardin, 1988). Durante a análise, buscou-se identificar fatores facilitadores e dificultadores da mudança em cada estágio e seus respectivos modos de enfrentamento, que foram transcritos em um quadro de análise e posteriormente categorizados.

\section{Resultados e Discussão}

\section{Estágio de contemplação}

Durante a fase de contemplação, os fatores que desencadearam e facilitaram a mudança foram predominantemente aversivos. Perdas familiares, ocupacionais, financeiras e de memória; necessidade de manter casamento; doença na família; isolamento social; apatia e internação em clínica psiquiátrica foram os principais fatores identificados nos relatos verbais dos participantes. O único fator não aversivo mencionado foi o nascimento de filhos (Quadro 1). Desses fatores, os mais freqüentes foram perdas vividas nos vários âmbitos relacionais.

Os fatores que dificultavam o fortalecimento da vontade de parar de beber eram principalmente conseqüências reforçadoras produzidas pelo beber, seja do tipo reforçador negativo (beber produzia esquiva de problemas) ou reforçador positivo (beber em situação de encontros sociais, familiares e de lazer). Além disso, a compulsão para beber e a não aceitação da condição de alcoolista foram citados como fatores dificultadores da vontade de parar de beber. As estratégias de enfrentamento relatadas nessa fase foram, em sua maioria, focadas no problema: buscar ajuda profissional; planejar parar de beber e fazer interrupções breves e ocasionais; seguidas das estratégias focadas na emoção: beber para acabar com a ressaca "moral" e fazer oração (Quadro 1).

Quadro 1. Fase de contemplação: frequência e tipo de fatores facilitadores e dificultadores da mudança e de estratégias de enfrentamento.

\begin{tabular}{|c|c|c|}
\hline Fator facilitador & Fator dificultador & Estratégias de enfrentamento \\
\hline Perdas: família, trabalho e dinheiro (4) & Esquiva de problemas através do beber (4) & $\begin{array}{l}\text { Orientação profissional durante internação } \\
\text { (2) }\end{array}$ \\
\hline $\begin{array}{l}\text { Nascimento filhos (2) } \\
\text { Perda de memória (2) }\end{array}$ & Beber associado a lazer (2) & $\begin{array}{l}\text { Interrupções ocasionais no uso da bebida } \\
\text { (2) }\end{array}$ \\
\hline $\begin{array}{l}\text { Manutenção do casamento (1) } \\
\text { Doença na família (1) }\end{array}$ & $\begin{array}{l}\text { Comportamento de beber entre familiares e } \\
\text { amigos ( } 2 \text { ) }\end{array}$ & $\begin{array}{l}\text { Planejar parar de beber (2) } \\
\text { Fazer oração (1) }\end{array}$ \\
\hline $\begin{array}{l}\text { Apatia advinda do beber (1) } \\
\text { Internações involuntárias (1) }\end{array}$ & Não aceitação da condição de alcoolista (1) & Beber para acabar com a ressaca "moral" (1) \\
\hline Isolamento social quando agressivo (1) & Compulsão para beber (1) & \\
\hline
\end{tabular}




\section{Estágio de preparação}

Na fase de preparação, os fatores facilitadores da decisão de parar de beber foram também do tipo aversivos, porém relatados como mais intensos do que aqueles vividos nos estágios anteriores. Por ordem de freqüência, foram citados: problemas de saúde; conflitos familiares; morar na rua; vergonha de ex-colegas de trabalho; acidente de trânsito com vítima e internação em clínica psiquiátrica de baixa qualidade. Fatores relatados como dificultadores da decisão de parar de beber foram a sensação de impotência frente ao beber; plano de suicídio; exclusão social e superproteção do cônjuge. A principal estratégia de enfrentamento usada nessa fase foi busca de suporte social em grupo de ajuda mútua, na família e entre amigos, seguida de comparação social ("se os outros conseguiram parar de beber eu também posso conseguir") e uso de droga ilícita (Quadro 2).

Coerentemente com a descrição da literatura (Miller \& Rollnick, 2001), esses resultados sugerem existir nos estágios de contemplação e preparação a ambivalência frente à decisão de parar de beber, já que são claramente percebidas vantagens e desvantagens do parar de beber, ou, em outras palavras, o beber é seguido por conseqüências reforçadoras e punitivas. O desejo de mudança surge quando o alcoolista é exposto a conseqüências altamente aversivas do beber: ou ele pára de beber ou perde mais ainda. Antes disso, parecem predominar as conseqüências "positivas": o beber produz reforçadores positivos tais como euforia e contatos sociais amistosos. Os dados fundamentam a pressuposição de que quando as conseqüências punitivas do beber superam em magnitude as conseqüências reforçadoras, é desencadeado o estágio de contemplação para parar de beber. Isso está em acordo com dados obtidos por Barnett, Lebeau-Craven, O'Leary, Colby, Woolard, Rohsenow, Spirito \& Monti (2002) em um estudo acerca de preditores da motivação para parar de beber em uma amostra de adolescentes atendidos em uma unidade de emergência de um hospital por problemas com álcool. Dentre os preditores encontrados, encontravam-se penalidades por ter quebrado as regras familiares quanto ao beber, severidade da lesão e número de conseqüências antecipadas, incluindo a previsão de conflitos com os pais.

Os dados obtidos acerca de fatores facilitadores e dificultadores da decisão de parar de beber e enfrentamento durante o estágio de preparação sugerem que: (a) o suporte social parece ser uma estratégia de enfrentamento eficaz, ao passo que a exclusão social dificulta a mudança, (b) a impotência diante da bebida parece revelar déficit em habilidades de autocontrole e enfrentamento de situações de risco para o beber, podendo até gerar o desejo de suicídio e (c) condutas superprotetoras do cônjuge dificultam a mudança e devem ser alvo de intervenção, seja em contextos profissionais ou não. A fase de preparação parece ser um momento decisivo para intervenção profissional, familiar ou social, para que a decisão de parar de beber possa se tornar ação. É provável que intervenções nessa etapa possam ser benéficas se concretizadas através do incremento da percepção de ganhos e perdas associados ao beber (Miller \& Rollnick, 2001), da percepção de suporte social (Sarason, Pierce

Quadro 2. Fase de preparação: frequência e tipo de fatores facilitadores e dificultadores da mudança e de estratégias de enfrentamento.

\begin{tabular}{lll}
\hline \multicolumn{1}{c}{ Fatores facilitadores } & Fatores dificultadores & Estratégias de enfrentamento \\
\hline $\begin{array}{l}\text { Problemas de saúde advindos do beber } \\
\text { (3) }\end{array}$ & Sensação de impotência frente ao beber (4) & Busca de apoio em grupo de ajuda mútua \\
Conflitos familiares (3) & Plano de suicídio (2) & Suporte social familiar (2) \\
Acidentes de trânsito (1) & Exclusão social (2) & Suporte social amigos (1) \\
Morar na rua após perdas familiares (1) & Proteção da esposa por erros conseqüentes ao & Suporte social durante primeiras reuniões \\
& beber (1) & do grupo de ajuda (1) \\
Ajuda profissional (1) & & Comparação social (1) \\
Vergonha de ex-colegas de trabalho (1) & Usar drogas ilícitas (1) \\
Internação em clínica psiquiátrica de & \\
baixa qualidade (1) &
\end{tabular}


\& Sarason, 1990) e da percepção de que há recursos passíveis de aprendizagem que poderão ser úteis para lidar com o abandono do uso do álcool.

\section{Estágio de ação}

Durante a fase de ação, os fatores que facilitaram o abandono do álcool foram principalmente o suporte social oferecido pelo grupo de ajuda mútua, seguido de fortalecimento de auto-eficácia, suporte social familiar, perda de todas as conquistas e fuga da exclusão social. O suporte social no grupo de ajuda mútua incluía a receptividade dos membros do grupo frente ao novo membro; ter acesso a material de leitura do grupo; ter acesso a informações confiáveis resultantes de experiências bem-sucedidas no abandono da bebida; poder se comparar a outros com problemas semelhantes e perceber saídas para si mesmo dado que o outro encontrou saídas; e poder expressar sentimentos negativos (exemplo: raiva, medo ou ressentimento) no grupo (Quadro 3).
Para parar efetivamente de beber, o grupo de ajuda mútua parece desempenhar papel relevante ao ensinar variadas estratégias de enfrentamento, antes desconhecidas. Além disso, pode-se inferir que é condição necessária para a mudança a aceitação dos problemas associados ao uso da bebida. A partir de tal aceitação, aprende-se um novo repertório de habilidades para lidar com situações de risco e minimizar a probabilidade de beber. Nota-se que o grupo ensina técnicas de autocontrole (evitar "velhos caminhos"), modificação de condições estabele-cedoras ligadas ao valor reforçador do beber (comer antes de sair de casa) e habilidades sociais (evitar conflitos familiares). Parece relevante contar com uma fonte de suporte social: o padrinho, para quem pode se telefonar a qualquer hora, sempre disponível a apoiar e sugerir possibilidades de enfrentamento. Os dados sugerem que o suporte social é uma das estratégias de enfrentamento mais usadas nos estágios de ação e manutenção, possivelmente por gerar um senso de aceitação pelo grupo, por incrementar a auto-eficácia, por minimizar ansiedade e outras emoções desconfortáveis, por

Quadro 3. Fase de ação: freqüência e tipo de fatores facilitadores e dificultadores da mudança e de estratégias de enfrentamento.

\begin{tabular}{lll}
\hline \multicolumn{1}{c}{ Fatores facilitadores } & \multicolumn{1}{c}{ Fatores dificultadores } & \multicolumn{1}{c}{ Estratégias de enfrentamento } \\
\hline $\begin{array}{l}\text { Suporte social em grupo de ajuda mútua } \\
\text { (5) }\end{array}$ & Compulsão para beber (3) & Esquiva de situações de risco para o beber \\
$\begin{array}{l}\text { Aumento em auto-eficácia (2) } \\
\text { Perda de todas as conquistas (2) }\end{array}$ & Inabilidade para lidar com a realidade (3) & Busca de padrinho no grupo (3) \\
$\begin{array}{l}\text { Fuga de exclusão social (1) } \\
\text { Suporte social familiar (1) }\end{array}$ & Comemorações (1) & Adesão às instruções do grupo de ajuda \\
& Atribuir ao outro culpa por problemas pessoais & mútua (3) \\
& Comer doce quando com vontade de beber \\
& Não aceitar ajuda (1) & (3) \\
& Estabelecer meta de abstinência a cada 24 \\
& hão aceitar perda do domínio da própria vida \\
& (1) & Assiduidade às reuniões do grupo (2) \\
& Consideração de conseqüências do beber \\
& (1) \\
& Buscar força espiritual (1) \\
& Comer antes de sair de casa (1) \\
& Resignação: consciência de mudança \\
& gradual e lenta (1) \\
& Usar outras drogas (1) \\
& Não tomar decisão em momento de \\
& dúvida (1) \\
& Isolar-se (1) \\
\hline
\end{tabular}


permitir compartilhar senti-mentos e favorecer a intimidade, o que supõe se sentir compreendido, validado e cuidado pelo grupo (Sarason, Pierce \& Sarason, 1990).

Fatores relatados como dificultadores do parar de beber na fase de ação foram: compulsão para beber; não se perceber com habilidades para lidar com a realidade e com situações de risco; não aceitar ajuda; atribuir ao outro culpa pelos próprios problemas e não aceitar perda do domínio da própria vida. Nessa fase, as estratégias de enfrentamento utilizadas foram bastante variadas e superiores em número às estratégias das fases de contemplação e preparação: freqüentar assiduamente as reuniões do grupo de ajuda mútua e seguir suas orientações; recorrer ao "padrinho" (uma pessoa responsável por ajudar ao membro recémchegado no grupo) em situações de risco; esquivar-se de situações de risco (evitar companhia de amigos e locais antes freqüentados e conflitos familiares, por exemplo); comer doce quando houver vontade de beber; comer antes de sair de casa; estabelecer meta de abstinência a cada 24 horas; considerar conseqüências do beber e do não beber comparando lembranças de bebedeiras passadas e a abstinência atual; buscar ajuda espiritual; resignar-se frente à lentidão e dificuldade das mudanças; não tomar decisões estando em dúvida; não se isolar e não usar outras drogas. Essas informações e suas respectivas freqüências estão evidenciadas na Quadro 3. Nessa fase, um participante recaiu por um período de vinte dias e outro por um período de seis meses, voltando em seguida à fase de ação.

\section{Estágio de manutenção}

O principal fator dificultador da manutenção do abandono do álcool foi expor-se a situações de risco, incluindo bares, festas, encontros irregulares com mulheres, pressão social (ter que dizer não, por exemplo) e lembranças do passado. Tais situações foram relatadas como situações de risco por gerarem emoções intensas como euforia, frustração, depressão, ansiedade ou ressentimento, sentimentos antes desencadeadores do beber. Além da exposição a situações de risco, também foram considerados fatores dificultadores: alcoolismo na família, lidar com agressividade verbal de familiares e autocobranças (Quadro 4).

Para manter-se não bebendo, todos os participantes relataram usar as estratégias de enfrentamento do tipo aderir à programação do grupo de ajuda mútua; buscar suporte social através do

Quadro 4. Fase de manutenção: freqüência e tipo de fatores dificultadores da mudança e estratégias de enfrentamento.

\begin{tabular}{|c|c|}
\hline Fatores dificultadores & Estratégias de enfrentamento \\
\hline Expor-se a situações de risco (3) & Aderir à programação do grupo de ajuda mútua (5) \\
\hline Alcoolismo na família (1) & Busca de suporte social (5) \\
\hline Autocobranças (1) & Práticas espirituais (5) \\
\hline \multirow[t]{14}{*}{ Lidar com agressão de familiares (1) } & Aceitar limites pessoais (4) \\
\hline & Consideração de conseqüências (3) \\
\hline & Antecipar e evitar situações de risco (3) \\
\hline & Resignação (3) \\
\hline & Aumento em auto-eficácia (3) \\
\hline & Comparação social (2) \\
\hline & Priorizar autocuidados (2) \\
\hline & Estabelecer objetivos a curto prazo (2) \\
\hline & Reparar erros (2) \\
\hline & Auto-revelação de sentimentos (1) \\
\hline & Humor (1) \\
\hline & Prestar serviço ao grupo de ajuda (1) \\
\hline & Perceber responsabilidade pessoal em conflitos interpessoais (1) \\
\hline & Isolar-se (1) \\
\hline
\end{tabular}


"padrinho" no grupo de ajuda mútua; melhorar convivência familiar; ser seletivo com amigos associados a situações de risco; participar da comunidade e adotar práticas espirituais quando em situações de risco. Também foram relatadas como estratégias de enfrentamento na fase de manutenção: lidar com autocobranças, aceitando limites pessoais; considerar conseqüências do beber lembrando das perdas resultantes do beber e ganhos resultantes do não beber; aceitar dificuldades inerentes ao processo de mudança (resignação); aumentar auto-eficácia pensando "eu posso não beber"; comparação social lembrando de amigos que recaíram e se suicidaram; priorizar autocuidados; estabelecer objetivos a curto prazo; reparar erros cometidos que atingiram outras pessoas; fazer auto-revelação de sentimentos no grupo ao se sentir deprimido; ter humor; prestar serviço ao grupo de ajuda; perceber responsabilidade pessoal em conflitos interpessoais e isolar-se quando em situação de risco (Quadro 4).

Os resultados apontam que estratégias focadas no problema (Lazarus \& Folkman, 1984) foram as mais utilizadas em todos os estágios de mudança em relação ao parar de beber a fim de lidar com as perdas e ganhos associados ao beber em cada um dos estágios que antecederam a ação e com as situações de risco para o beber nos estágios de ação e manutenção. Isso sugere que o parar de beber é avaliado como uma situação passível de ser mudada, em oposição a situações percebidas como inalteráveis em que é mais comum o uso de estratégias focadas na emoção (Antoniazzi, Dell'Agio \& Bandeira, 1998). Contudo, há de se salientar que o engajamento em estratégias focadas no problema, como pedir orientação a um membro do grupo de ajuda sobre como lidar com a pressão de antigos colegas de bar, pode gerar efeitos em parte semelhantes àqueles gerados pelo uso de estratégias focadas na emoção, no sentido de reduzir emoções desconfortáveis. Por outro lado, o uso de estratégias focadas na emoção, como o engajamento em práticas espirituais, pode facilitar, por exemplo, o planejamento e as tomadas de decisão, tarefas tidas como resultantes de estratégias de enfrentamento focadas no problema. Como lembrado por Antoniazzi, Dell'Agio e Bandeira (1998), um mesmo comportamento pode ter a função de focalização no problema e na emoção, o que torna ambígua a classificação de enfrentamento focado no problema e na emoção. Esse é um problema conceitual a ser tratado em estudos destinados ao aprimoramento da teoria sobre enfrentamento.

As estratégias de enfrentamento usadas nos estágios de ação e manutenção, superiores em freqüência de relatos do que as estratégias descritas nos estágios de contemplação e preparação, sugerem que quanto melhor o enfrentamento melhor a manutenção da mudança, o que confirma achados de Maisto, Connors e Zywiak (2000). Para manter mudanças, foram relatadas inúmeras estratégias de enfrentamento utilizadas, tanto do tipo focadas no problema (buscar suporte social, antecipar e evitar situações de risco, planejar metas a curto prazo, aumentar auto-eficácia, reparar erros, priorizar autocuidados, considerar conseqüências da ação) quanto focadas na emoção (expressar sentimentos no grupo, aceitar limites pessoais, humor, exercitar espiritualidade, isolar-se). Além da vontade de parar de beber, é necessário saber o que fazer, quando fazer e como fazer para engajar-se em comportamentos alternativos ao beber sem recair.

\section{Conclusão}

Os resultados sobre as diferenças entre as estratégias de enfrentamento em cada estágio corroboram a literatura no que se refere ao enfrentamento como um processo dinâmico e situacional (Cerqueira, 2000): estágios de mudança diferentes impõem demandas estressoras distintas que requerem também estratégias de enfrentamento específicas.

Dentre as limitações deste estudo, encontra-se a avaliação retrospectiva de dados, já que os participantes estavam em manutenção há, pelo menos, três anos e foram solicitados a lembrar e descrever como haviam vivido os estágios de mudança em relação ao beber. Dados fundamentados em recordação podem estar sujeitos a diversos viéses capazes de alterar a precisão das informações (Antoniazzi, Dell'Agio \& Bandeira,1998; Kunda, 1998; Cerqueira, 2000). Novos estudos poderão usar delineamentos longitudinais voltados para o acompanhamento de pessoas recém-chegadas a grupos de ajuda mútua e seu seguimento, ou estudos transversais com indivíduos que estejam vivenciando 
estágios diferentes de mudança em relação ao parar de beber, de modo a se identificarem especificidades em modos de enfrentamento entre aqueles que chegam à fase de manutenção e aqueles que recaem ao longo do percurso, sem se basear somente em relatos de memória. Outra limitação foi o recrutamento feito apenas em um grupo de ajuda. Pode-se supor que isso tenha enviesado os resultados acerca do peso do suporte social como estratégia de enfrentamento. Fontes diversificadas de recrutamento devem ser usadas em estudos futuros para verificar essa pressuposição.

Para novos estudos, amostras maiores são recomendadas com uso conjugado de metodologias qualitativas, como grupos focais (Seal, Bogart \& Ehrhardt, 1998), e quantitativas, como o uso de escalas. Estudos de caso, como o descrito neste artigo, poderão subsidiar a construção de instrumentos para uso em grupos maiores.

Este estudo de caso ofereceu indícios de que o Modelo de Mudança Transteórico pode ser útil para descrever estratégias de enfrentamento em cada estágio de mudança do parar de beber. Além disso, os dados confirmam a tendência descrita na literatura em intervenção junto a alcoolistas em fases de contemplação e preparação, isto é, adotar procedimentos terapêuticos para o incremento da percepção das conseqüências reforçadoras e aversivas do beber pode favorecer o processo de mudança (Miller \& Rollnick, 2001). Outros elementos, se agregados a tais programas de intervenção, poderão ser benéficos, como (a) o oferecimento de orientação familiar para que sejam evitadas condutas excludentes e superprotetoras em qualquer dos estágios, (b) a ampliação do repertório de auto-observação e identificação de situações de alto risco (Marlatt \& Gordon,1993; Knapp \& Bertolote, 1994), (c) o aprendizado de estratégias de enfrentamento focadas no problema para pessoas que estejam nas fases de ação e manutenção e (d) a busca de suporte social em qualquer dos estágios de mudança (Read, Kahler \& Stevenson, 2001). Dados relativos a situações de alto risco e estratégias de enfrentamento também poderão ser usados em programas preventivos junto a adolescentes no contexto escolar ou outros (Repucci, Woolard \& Fried, 1999; Gómez, 2001). Novos estudos poderão examinar a viabilidade e efeitos de tais propostas interventivas.

\section{Referências}

Antoniazzi, A.S., Dell'Agio, D.D., \& Bandeira, D.R. (1998). O conceito de coping: uma revisão teórica. Estudos de Psicologia, 3, 273-294.

Bardin, L. (1977/1988). Análise de conteúdo. Lisboa: Edições 70.

Barnett, N.P., Lebeau-Craven, R., O'Leary, T.A., Colby, S.M., Woolard, R., Rohsenow, D.J., Spirito, A., \& Monti, P.M. (2002). Predictors of motivation to change after medical treatment for drinking-related events in adolescents. Psychology of Addictive Behaviors, 16 (2), 106-112.

Cerqueira, A.T.A.R. (2000). O conceito e metodologia de coping: existe consenso e necessidade? In R.R. Kerbauy (Org.). Sobre comportamento e cognição. Conceitos, pesquisa e aplicação, a ênfase no ensinar, na emoção e no questionamento clínico (pp.279-289). Santo André: SET.

DiClemente, C.C., \& Prochaska, J.O. (1982). Self change and therapy change of smoking behavior: A comparison of processes of change in cessation and maintenance. Addictive Behaviors, 7 (2), 133-142.

DiClemente, C.C., Prochaska, J.O., Fairhurst, S.K., Velicer, W.F., Velasquez, M.M., \& Rossi, J.S. (1991). The process of smoking cessation. An analysis of precontemplation, contemplation, and preparation stages of change. Journal of Consulting and Clinical Psychology, 59 (2), 295-304.

Gómez, J.L.G. (2001). Análise dos fatores de risco e proteção para o consumo de drogas em adolescentes. In M.L. Marinho \& V.E. Caballo (Orgs.). Psicologia clínica e da saúde (pp.55-75). Londrina/Granada: UEL/APICSA.

Jungerman, F.S., \& Laranjeira, R. (2001). Entrevista motivacional. A teoria e uma experiência de sua aplicação em grupos. In G.R.A. Focchi, M.C. Leite, R. Laranjeira \& A.G. Andrade (Orgs.). Dependência química. Novos modelos de tratamento (pp.19-48). São Paulo: Roca.

Knapp, P., \& Bertolote, J.M. (1994). Prevenção da recaída. Um manual para pessoas com problemas pelo uso do álcool e de drogas. Porto Alegre: Artes Médicas.

Kunda, Z. (1998). Social cognition: making sense of people. Cambridge: Massachusetts Institute of Technology Press.

Lazarus, R.S., \& Folkman, S. (1984). Stress, appraisal and coping. New York: Springer Publishing Company.

Lichtenstein, E., \& Glasgow, R.E. (1992). Smoking cessation: what have we learned over the past decade? Journal of Consulting and Clinical Psychology, 60 (4), 518-527.

Maisto, S.A., Connors, G.L., \& Zywiak, W.H. (2000). Alcohol treatment, changes in coping skills, self-efficacy, and levels of alcohol use and related problems 1 year following treatment initiation. Psychology of Adictive Behaviors, 14 (3), 257-266

Marlatt, A.G., Larimer, M.E., Baer, J.S., \& Quigley, L.A. (1993). Harm reduction for alcohol problems: moving beyond the controlled drinking controversy. Behavior Therapy, 24, 461-504.

Marlatt, G.A., \& Gordon, J.R. (1993). Prevenção da recaída. Estratégia e manutenção no tratamento de comportamentos adictivos. Porto Alegre: Artes Médicas. 
Miller, W.R., \& Rollnick, S. (2001). Entrevista motivacional. Preparando as pessoas para a mudança de comportamentos adictivos. Porto Alegre: ArtMed.

O'Farrel, T.J., Choquette, K.A., Gutter, H.S.G., Brown, E., Bayog, R., McCourt, W., Lowe, J., Chan, A., \& Deneault, P. (1996). Cost-benefit and cost-effectiveness analyses of behavioral marital therapy with and without relapse prevention sessions for alcoholics and their spouses. Behavior Therapy, 27, 4-6.

O'Farrel, T.J., Gutter, H.S.G., Choquette, K.A., Floyd, F.J., \& Bayog, R.D. (1992). Behavioral marital therapy for male alcoholics: marital and drinking adjustment during the two years after treatment. Behavior Therapy, 23, 507-528.

Oldenburg, B. (1994). Promotion of health: Integrating the clinical and public health approaches. In S. Maes, H. Leventahl \& M. Johnston (Eds.). International review of health psychology (v.3, pp.121-143). New York: Wiley.

Orleans, C.T. (2000). Promoting the maintenance of health behavior change: recommendations for the next generation of research and practice. Health Psychology, 19 (1 Suppl), 76-83.

Pers, C.A., DiClemente, C.C., \& Carbonari, J.P. (1996). Doing the right thing at the right time? The interaction of stages and processes of change in successful smoking cessation. Health Psychology, 15 (6), 462-468.

Prochaska, J.O., \& DiClemente, C.C. (1983). Stages and processes of self-change of smoking: toward na integrative model of change. Journal of Consulting and Clinical Psychology, 51 (3), 390-395.
Prochaska, J.O., DiClemente, C.C., \& Norcross, J.C. (1992). In search of how people change. Aplications to addictive behaviors. Americam Psychologist, 47 (9), 1102-1114.

Prochaska, J.O., Redding, C.A., \& Evers, K.E. (1997). The transtheoretical model and stages of change. In K. Glanz, F.M. Lewis \& B.K. Rimer (Eds.). Health behaviour and health education. Theory, research, and practice (pp.60-84). San Francisco: Jossey-Bass Publishers.

Read, J.P., Kahler, C.W., \& Stevenson, J.F. (2001). Bridging the gap between alcoholism treatment research and practice: identifying what works and why. Professional Psychology: Research and Practice, 32, 227-238.

Repucci, N.D., Woolard, J.L., \& Fried, C.S. (1999). Social, community, and preventive interventions. Annual Review of Psychology, 50, 387-418.

Sarason, B.R., Pierce, G.R., \& Sarason, I.G. (1990). Social support: the sense of acceptance and the role of relationships. In B.R. Sarason; I.G. Sarason \& G.R. Pierce (Orgs.). Social support:an interactional view(pp.97-128). New York: John Wiley \& Sons.

Seal, D.W., Bogart, L.M., \& Ehrhardt, A.A. (1998). Small group dynamics: the utility of focus group discussions as a research method. Group Dynamics: Theory, Research, and Practice, 2, 253-266.

Sobell, M.B., Sobell, L.C., \& Gavin, D.R. (1995). Portraying alcohol treatment outcomes: different yardstricks of sucess. Behavior Therapy, 26, 643-670.

Yoshida, E.M.P. (2002). Escala de estágios de mudança: uso clínico e em pesquisa. Psico-USF, 7, 59-66.

Recebido para publicação em 28 de maio de 2004 e aceito em 1 de abril de 2005. 